\title{
Self-treatment of Uncomplicated Malaria at Community Level in Masala Township, Ndola District, Zambia: Prevalence, Knowledge and Factors Influencing Self-treatment
}

\section{Chansa Mulenga* and Boniface Kawimbe}

Copperbelt University, School of Medicine, Ndola Campus, Zambia

\begin{abstract}
Background: Malaria is the commonest cause of fever, morbidity and mortality in the tropics. A good number of people are able to recognize the symptoms and initiate treatment. However lack of clinical evaluation of the patients by trained health professionals, may delay appropriate treatment and promote drug resistant.

Objective: To determine the prevalence of self-treatment of malaria among the people with regard to knowledge and factors that may influence health seeking behavior.

Method: Community based cross section descriptive study carried among 365patients buying medicines from local drugstores. A structured questionnaire was used to gather data entered in Epi Data 3.1 and analysis done using SPSS version 16.0. To ascertain association between dependent and independent variables, binary logistic regression and variables with $p$-value of less than or equal to 0.05 were entered into multivariate regression analysis.
\end{abstract}

Results: Among the 365 patients interviewed 150 bought antimalarials 150/365 (41.1\%).

The overall knowledge was $44.7 \%$ and significantly associated with income, education and occupation. Compared to respondents with income $>\mathrm{K} 1000$, respondents with income

$<\mathrm{K} 500$ were $94 \%$ (AOR=0.06; $95 \% \mathrm{Cl}[0.01,0.21])$ less likely to be knowledgeable.

Respondents with tertially education were $2.73(95 \% \mathrm{Cl}[1.50,4.89])$ times more likely to be knowledgeable compared to respondents with primary education. Compared to respondents with others ${ }^{\text {a }}$ occupations, professionals were $5.97(95 \% \mathrm{Cl}[2.27,15.7])$ times more likely to be knowledgeable. Sulfadoxine-pyrimethamine (fansidar) is by far the antimalaria drug that was used $51.3 \%$. About $66.7 \%$ attributed to overcrowding and $72.7 \%$ to not being attended to in less than 2 hours upon arrival at health facility as reasons for not seeking treatment at government facilities.

Conclusion: Prevalence of self-medication was high $41.1 \%$ and most people lacked adequate knowledge on malaria. The individual's level of formal education, income and occupation were determinants knowledge.

Keywords: Malaria; Self-medication; Knowledge; Drugstore; Antimalarial

\section{Introduction}

Malaria is a serious global problem, particularly in tropical countries where it is one of the major causes of morbidity and mortality. It is the commonest cause of fever, morbidity and a significant source of mortality, especially among infants and young children [1]. Every year, malaria causes clinical illness, often very severe in 300-500 million people and over a million people die from it. It threatens 2.2 billion people, which is about $40 \%$ of the world's population, undermining the health and welfare of the families, endangering the survival, straining both national and people's scarce resources [2,3].

In Zambia, malaria is a major public health problem. It is the leading cause of health visits and hospital deaths, accounting for $4-5 \%$ of hospital deaths. At risk of severe illness are the pregnant women and under-five children [4]. Most people are able to recognize the symptoms of malaria and usually initiate treatment. However the disadvantage of self-treatment is the lack of clinical evaluation by trained health professionals, which could result in delay of appropriate treatment. The promotion of drug resistant Plasmodium falciparum because of the widespread use of antimalarials in cases of under dosing and the risks associated with potentially toxic doses of these drugs are other possible disadvantages.
Many reasons have been cited for the increase in the number of people initiating self-treatment of malaria, among these being availability of antimalarial drugs and ease of access to the medicines without documentation and inadequate number of health workers has necessitated overcrowding at health centres making patients avoid long queues.

Incorrect use of anti-malaria drugs has resulted in increased disease burden and deaths from malaria (through recurrences, recrudescence and development of drug resistance). This is one of the reasons why the morbidity and mortality due to malaria is high despite anti-malaria

\section{*Corresponding author: Chansa Mulenga, Copperbelt University, Schoo of Medicine, Ndola Campus, Zambia;Tel: +260 212 614327; E-mail: mulengachansa93@yahoo.co.uk}

Received July 13, 2015; Accepted September 24, 2015; Published October 01, 2015

Citation: Mulenga C, Kawimbe B (2015) Self-treatment of Uncomplicated Malaria at Community Level in Masala Township, Ndola District, Zambia: Prevalence, Knowledge and Factors Influencing Self-treatment. Malar Cont Elimination 4: 133. doi: 10.4172/2470-6965.1000133

Copyright: (c) 2015 Mulenga C, et al. This is an open-access article distributed under the terms of the Creative Commons Attribution License, which permits unrestricted use, distribution, and reproduction in any medium, provided the original author and source are credited. 
drugs particularly sulfadoxine-pyrimethamine being readily available in communities [5].

A hospital-based study in Tanzania where $72.7 \%$ of patients reported having used home kept antimalaria medication for suspected malaria fever [6]. In Kilifi district of Uganda, uptake of sufadoxinepyrimethamine as constrained by widely held beliefs within the community that chloroquine was still effective [7]. In Bungoma district of Uganda, the community believed that sufadoxine-pyrimethamine was too strong for children under one year and therefore opted to buy alternative, but ineffective medicines, to protect children from the perceived strong effects of the drug [8].

It is against this background that the study aimed at investigating antimalarial self-medication in the community was done. It was hoped to help determine the prevalence of self-treatment of malaria among people with regard to knowledge and practices or factors that may influence patterns of health seeking behaviour.

\section{Materials and Methods}

\section{Study area}

Study done in Masala Township a high densely populated urban area of Ndola district. Has a total population of 36,000 people, consisting of people of middle and low socio-economic status.

\section{Study type, sample size, sampling procedures}

Cross section descriptive study carried out between January and April 2015. A sample size of 365 people calculated using epi info. Systematic random sampling was employed to gather information from patients buying medicines from Pharmacies, drug stores and vendors within the community.

\section{Data collection}

Qualitative and quantitative methods were used. The survey employed a structured questionnaire that was used in a face-to-face interview to gather data from the community member's accessing drugs from pharmacies, drug stores and drug vendors within the community.

\section{Data analysis}

All the data collected was entered into a database from the time it was collected in the field. Data was entered in Epi Data 3.1 and analysed using SPSS version 16.0. Statistical tests included Chi-square test and association between measured variables was considered to be significant at P-value equal-to or less than 0.05 . To ascertain association between dependent and independent variables, binary logistic regression and variables with $p$-value of less than or equal to 0.05 were entered into multivariate regression analysis. Knowledge was computed by adding the total score in which correct equals one and wrong zero (cut off point $=2 / 3$ ).

\section{Ethical consideration}

The research was approved by the Copper belt University School of Medicine, Public health department. Verbal consent was obtained from the participants.

\section{Results}

\section{Social demographics}

The survey conducted included total number 365 patients visiting the drugstore outlets to buy medicines and out of these, 150 had requested to buy antimalarial drugs giving the prevalence of $150 / 365$
(41.1\%) of antimalarial self-medication.

The sex distribution of patients with malaria in the surveyed was $77 / 150(51.3 \%)$ males and $73 / 150(48.7 \%)$ females. The largest proportion of patients were those aged above15 years 108/150 (72.0\%) representing 53/77 (68.8\%) males and 55/73 (75.3\%) females. Therefore, females were more likely to be older than males (Table 1).

Among the surveyed $26.7 \%$ had primary school education, $53.3 \%$ had secondary school education and $20.0 \%$ had tertiary education.

Most of the interviewed patients were businessmen/women 50.6\% while $14.0 \%$ were professionals, $15.3 \%$ housewives and $20.0 \%$ others (Table 1).

The percentage age distribution was $6.0 \%$ in below 5years, $22.0 \%$ between 5-15years, $72.0 \%$ above 15 years (Table 1 ).

The average monthly expenditure of the surveyed was between K500 - K1000 representing 48.0\% of the patients whilst those earning the least had income below K500 representing 27.3\%. Among the respondents, $24.7 \%$ earned above the average monthly income and of these $29.9 \%$ represented males (Table 1).

\section{Factors associated with knowledge on malaria}

Of the patients self-treating for malaria, only $67 / 150$ (44.7\%) had satisfactory knowledge (cause of malaria, diagnosis and recommended 1st line drug for uncomplicated malaria by ministry of health Zambia) on malaria.

The knowledge increased with the level of formal education acquired, the largest proportion was for respondents who had attained tertiary education $70.0 \%$ than those with secondary education $45.0 \%$ or primary education $25.0 \%$ (Table 2 ).

The respondents income level was noted to be factor that influenced knowledge with those earning income below K500 being 1/41 (2.4\%) knowledgeable, those between K500-k1000 being 37/72 (51.4\%), those above K1000 being 29/37 (78.4\%) knowledgeable (Table 2).

Professionals were likely to be more knowledgeable on malaria representing 18/21 (85.7\%) than housewives 9/23 (39.1\%), business men/women $32 / 76(42.1 \%)$ or the uncategorized occupations $8 / 30$ (26.7\%) (Table 2). Multivariable logistic regression showed that income, education, occupation had significant association with knowledge. Compared to respondents income $>\mathrm{K} 1000$, respondents with income $<\mathrm{K} 500$ were $94 \%$ (AOR=0.06; 95\% CI [0.01, 0.21]) less likely to be knowledgeable. Respondents with tertially education were 2.73 (95\% CI $[1.50,4.89])$ times more likely to be knowledgeable compared to respondents with primary education. Compared to respondents with others $^{\mathrm{a}}$ (uncategorized occupations), professionals were 5.97(95\% CI $[2.27,15.7])$ times more likely to be knowledgeable (Table 3 ).

\section{Anti-malaria drugs utilization}

The survey has shown that sulfadoxine-pyrimethamine (fansidar) is by far the antimalarial drug that was used for self-medication by patients in the study at $51.3 \%$ of the malaria episodes, coartem $36.7 \%$, quinine $2.0 \%$ and others ${ }^{\mathrm{b}} 10.0 \%$. The main reason given by the respondents for the choice of drug bought was the cost 57/150 (38.0\%), other reasons included effectiveness $52 / 150(34.7 \%)$, duration of treatment $37 / 150$ (24.7\%) and others ${ }^{c} 4 / 150$ (2.7\%) (Table 4).

\section{Information on malaria}

All the patients interviewed reported having received some form 


\begin{tabular}{|c|c|c|c|}
\hline Characteristic & $\begin{array}{c}\text { Total } \\
n=150(100 \%)\end{array}$ & $\begin{array}{c}\text { Male } \\
77(100 \%)\end{array}$ & $\begin{array}{c}\text { Female } \\
73(100 \%)\end{array}$ \\
\hline \multicolumn{4}{|l|}{ Age group } \\
\hline$<5$ year & $9(6.0)$ & $4(5.2)$ & $5(6.8)$ \\
\hline $5-15$ years & $33(22.0)$ & $20(26.0)$ & $13(17.8)$ \\
\hline$>15$ years & $108(72.0)$ & $53(68.8)$ & $55(75.3)$ \\
\hline \multicolumn{4}{|l|}{ Income } \\
\hline$<\mathrm{K} 500$ & $41(27.3)$ & $11(14.3)$ & $30(41.1)$ \\
\hline K500 - K1000 & $72(48.0)$ & $43(55.8)$ & $29(39.7)$ \\
\hline$>$ K1000 & $37(24.7)$ & $23(29.9)$ & $14(19.2)$ \\
\hline \multicolumn{4}{|l|}{ Educational level } \\
\hline Tertiary & $30(20.0)$ & $21(27.3)$ & $9(12.3)$ \\
\hline Secondary & $80(53.3)$ & $44(57.1)$ & $36(49.3)$ \\
\hline Primary & $40(26.7)$ & $12(15.6)$ & $28(38.4)$ \\
\hline \multicolumn{4}{|l|}{ Occupation } \\
\hline Professional & $21(14.0)$ & $15(19.5)$ & $6(8.2)$ \\
\hline Housewife & $23(15.3)$ & $0(0.0)$ & $23(31.5)$ \\
\hline businessman/woman & $76(50.6)$ & $42(54.5)$ & $34(46.6)$ \\
\hline Others ${ }^{a}$ & $30(20.0)$ & $20(26.0)$ & $10(13.7)$ \\
\hline
\end{tabular}

Table 1: Demographic characteristics of patients self-treating for malaria $n=150$

\begin{tabular}{|c|c|c|c|}
\hline Characteristic & $\begin{array}{c}\text { Interviewed } \\
n=150(100 \%)\end{array}$ & $\begin{array}{c}\text { Knowledgeable } \\
(100 \%)\end{array}$ & P Value \\
\hline Sex & \multirow{2}{*}{$\begin{array}{l}77(51.3) \\
73(48.7)\end{array}$} & \multirow[b]{2}{*}{$\begin{array}{l}34(44.2) \\
33(45.2)\end{array}$} & \multirow[b]{2}{*}{$=0.897$} \\
\hline $\begin{array}{l}\text { Male } \\
\text { Female }\end{array}$ & & & \\
\hline Age group & \multirow[b]{2}{*}{$\begin{array}{c}9(6.0) \\
33(22.0) \\
108(72.0)\end{array}$} & \multirow[b]{2}{*}{$\begin{array}{c}5(55.6) \\
11(33.3) \\
51(47.2)\end{array}$} & \multirow[b]{2}{*}{$=0.296$} \\
\hline $\begin{array}{l}<5 \text { year } \\
5-15 \text { years } \\
>15 \text { years }\end{array}$ & & & \\
\hline Income & \multirow[b]{2}{*}{$\begin{array}{l}41(27.3) \\
72(48.0) \\
37(24.7)\end{array}$} & \multirow[b]{2}{*}{$\begin{array}{c}1(2.4) \\
37(51.4) \\
29(78.4)\end{array}$} & \multirow[b]{2}{*}{$<0.001$} \\
\hline $\begin{array}{c}<\mathrm{K} 500 \\
\mathrm{~K} 500-\mathrm{K} 1000 \\
>\mathrm{K} 1000\end{array}$ & & & \\
\hline $\begin{array}{l}\text { Educational } \\
\text { level }\end{array}$ & \multirow{2}{*}{$\begin{array}{l}30(20.0) \\
80(53.3) \\
40(26.7)\end{array}$} & \multirow{2}{*}{$\begin{array}{l}21(70.0) \\
36(45.0) \\
10(25.0)\end{array}$} & \multirow[b]{2}{*}{$<0.001$} \\
\hline $\begin{array}{l}\text { Tertiary } \\
\text { Secondary } \\
\text { Primary }\end{array}$ & & & \\
\hline Occupation & \multirow[b]{2}{*}{$\begin{array}{l}21(14.0) \\
23(15.3) \\
76(50.6) \\
30(20.0)\end{array}$} & \multirow[b]{2}{*}{$\begin{array}{c}18(85.7) \\
9(39.1) \\
32(42.1) \\
8(26.7)\end{array}$} & \multirow[b]{2}{*}{$<0.001$} \\
\hline $\begin{array}{c}\text { Professional } \\
\text { Housewife } \\
\text { businessman/ } \\
\text { woman } \\
\text { Others }^{\mathrm{a}}\end{array}$ & & & \\
\hline
\end{tabular}

Table 2: Association between social demographic factors and knowledge of malaria management $\mathrm{n}=150$.

of information on malaria. The major single source of information on malaria reported was the health facility $34.7 \%$, radio/television $22.7 \%$, others ${ }^{\mathrm{d}} 4.0 \%$ whilst information from family and friends was $38.6 \%$ constituting a very big percentage. The information represented different drugs used in malaria $46.0 \%$, use of protective measures such as insecticide treated nets $28.0 \%$, signs and symptoms $15.3 \%$, dangers of the disease $8.0 \%$ and others ${ }^{\mathrm{e}} 2.7 \%$ (Table 4 ).

\section{Factors influencing self-treatment}

Table 5 describes the reasons why patients did not seek treatment at government health facilities, $10.0 \%$ mentioned long distance from the

\begin{tabular}{|c|c|}
\hline Factors & $\begin{array}{c}\text { AOR } \\
(95 \% \mathrm{Cl})\end{array}$ \\
\hline Income & \multirow{2}{*}{$0.06(0.01,0.21)^{\star}$} \\
\hline$<\mathrm{K} 500$ & \\
\hline $\mathrm{K} 500-\mathrm{K} 1000$ & $2.31(1.06,5.01)^{*}$ \\
\hline$>\mathrm{K} 1000$ & 1 \\
\hline Educational level & \multirow{2}{*}{$2.71(1.50,4.89)^{\star}$} \\
\hline Tertiary & \\
\hline Secondary & $0.95(0.60,1.51)^{\star}$ \\
\hline Primary & 1 \\
\hline Occupation & \multirow{2}{*}{$5.97(2.27,15.7)^{\star}$} \\
\hline Professional & \\
\hline Housewife & $0.64(0.31,1.34)^{\star}$ \\
\hline Businessman/woman & $0.72(0.42,1.25)^{\star}$ \\
\hline Othersa & 1 \\
\hline
\end{tabular}

Table 3: Factors associated with knowledge of malaria management in a multivariate logistic regression in Masala, Ndola, Zambia.NB: *statistically significant association at $\mathrm{P}$-value of $<0.05$.

\begin{tabular}{|c|c|}
\hline Question & Frequency $150(100 \%)$ \\
\hline Anti-malaria drugs bought & \multirow{2}{*}{$55(36.7)$} \\
\hline Coartem( atermether- lumefantrin) & \\
\hline Sulfadoxine-pyrimethamine (Fansidar) & $77(51.3)$ \\
\hline Quinine & $3(2.0)$ \\
\hline Others $^{b}$ & $15(10.0)$ \\
\hline $\begin{array}{l}\text { Reasons given for choice of } \\
\text { particular anti-malaria }\end{array}$ & \multirow[t]{2}{*}{$52(34.7)$} \\
\hline Cost & \\
\hline Effectiveness Duration of the treatment & $37(24.7)$ \\
\hline Others $^{c}$ & $4(2.7)$ \\
\hline Sources of information on malaria & \multirow{2}{*}{$34(22.7)$} \\
\hline Television/Radio & \\
\hline Health facility & $52(34.7)$ \\
\hline Relatives & $26(17.3)$ \\
\hline Friends & $32(21.3)$ \\
\hline Others $^{d}$ & $6(4.0)$ \\
\hline Type of information received & \multirow{2}{*}{$69(46.0)$} \\
\hline Drugs used & \\
\hline Dangers & $12(8.0)$ \\
\hline Signs and symptoms & $23(15.3)$ \\
\hline Use of protective measures & $42(28.0)$ \\
\hline Others ${ }^{e}$ & $4(2.7)$ \\
\hline
\end{tabular}

Table 4: Antimalarial drug utilization and sources of information $n=150$.

health centre, $66.7 \%$ mentioned overcrowding at the facilities, $22.0 \%$ mentioned lack of proper treatment at the government health facilities and $1.3 \%$ said they could not afford treatment.

The study has shown that $72.7 \%$ of the patients admitted to not being attended to in less than 2 hours upon arrival at the health facility by health centre staff and $42.7 \%$ of the patients were not able to reach the nearest health centre within 1 hour of walking (Table 5).

\section{Discussion}

The survey conducted showed prevalence of 150/365 (41.1\%) antimalarial self-medication among the community members. A similar study done in Tanzania by Kigochi Neg Kigochi(MD) in titled "Malaria and anti-malaria drug utilization among adults in rural coastal community in Tanzania, knowledge, attitudes and practices - 2005", 


\begin{tabular}{|c|c|}
\hline Question & Frequency 150 (100\%) \\
\hline $\begin{array}{c}\text { Why patients do not seek treatment } \\
\text { at the health facility }\end{array}$ & $15(10.0)$ \\
\hline Long distance & $100(66.7)$ \\
\hline Overcrowding & $33(22.0)$ \\
\hline $\begin{array}{c}\text { cannot afford } \\
\text { do not receive proper treatment } \\
\text { facility } \\
\text { within 2 hours upon arrival } \\
\text { Yes }\end{array}$ & $2(1.3)$ \\
\hline No & $41(27.3)$ \\
\hline $\begin{array}{c}\text { Patients ability to reach closest } \\
\text { health facility } \\
\text { within 1 hour of walking }\end{array}$ & $109(72.7)$ \\
\hline Yes & $86(57.3)$ \\
\hline No & $64(42.7)$ \\
\hline
\end{tabular}

Table 5: Factors influencing self-treatment of malaria $n=150$.

Others $^{a}=$ Famers, House help or servant, Shop keepers

Others $^{\mathrm{b}}=$ Coarinate, Amodiaquine

Others ${ }^{c}=$ Recommended by a relative, Drugs given at health centre before

Others $^{\mathrm{d}}=$ Newspapers, Roadside poster

Others ${ }^{e}=$ Laviciding, Spraying in houses, Mosquito repellents

showed a prevalence of $44.2 \%$ of self-medication with antimalarials which is in correlation with this study [9].

The sex distribution of patients self-medicating with antimalarials in the surveyed was almost an even score representing $51.3 \%$ males and $48.7 \%$ females. This showed that the incidence of malaria episodes in the area of study to be independent of sex.

The percentage age distribution was higher in those above 15years representing $72.0 \%$, the observation showed significant variation across age groups and may be attributed to the fact that parents or guardians would prefer to take younger children to the government health centre as opposed to self-treating them. The lower incidence in those below 5 years could also be due to the increase in the contact time between children and health workers through

programs that are available for children at the health centres such under five immunization programs, child health week, protection accorded by maternal antibodies or maximum parental care (sleeping in insecticide treated mosquito nets).

The majority of the interviewed were patients whose occupation was trading (businessman/woman) 50.6\%, the association between self-medication and respondent's occupation probably signifies that certain occupations may be more predisposed to self-medication than others. This would reflect on the responses in that people involved in trading are usually busy with their business and that they would look for quicker ways of attending to their illness such as self-treatment. The overall knowledge was $44.7 \%$ and increased with increasing level of education, income and occupation, as these subjects were likely to be more exposed to information about malaria and be better informed on the appropriate medication than those with low level of education or income. The knowledge was satisfactory among professionals representing $85.7 \%$ compared to housewives, businesspersons and others ${ }^{\mathrm{a}}$. Professionals could be more educated and have more exposure to information on malaria and understanding of the disease, this means that improving factors such as the level of formal education in the community would reduce the rate of morbidity and mortality.

The patient's interviewed used clinical methods to diagnose malaria, the failure to confirm malaria with laboratory methods may lead to other illnesses that present with similar symptoms being treated as malaria which could result in missed diagnosis and delay appropriate treatment which can be fatal. The symptoms of malaria are rather non-specific and occur with most other common infections such as influenza, typhoid, viral hepatitis, dengue or fever of unknown origin e.g. tuberculosis.

The survey showed that sulfadoxine-pyrimethamine (fansidar) was by far the anti-malaria drug used by most patients in self-medication as it was used by most of the respondents in the malaria episodes representing $51.3 \%$ compared to coartem $36.7 \%$ which is the 1 st line recommended drug for treatment of uncomplicated malaria by ministry of health Zambia and the main reason for the choice of drugs bought was the cost $38.0 \%$. All the patients interviewed reported having received some form of information on malaria.

The single major source of information on malaria reported was the health facility $34.7 \%$ whilst information from family and friends represented $38.6 \%$ which constituted a very big percentage and the worry being that the information may be inaccurate and distorted. Inquiry on why the patients would at times not seek treatment at government health facilities .revealed the majority $66.7 \%$ mentioned overcrowding at the facilities. The issue of overcrowding making patients not going to seek treatment at government health facilities was also reflected when we looked at the number of patients $72.7 \%$ not being attended to by health centre staff in less than 2hours upon arrival at the health facility.

\section{Conclusion}

The prevalence of self-medication was high among the residents of Masala Township representing $41.1 \%$. The knowledge on the disease was low, in particular those with low levels of income, education and occupation. The larger proportion of patients who were self-treating was that of those above 15years which may signify reduced access to government health facilities in the older age group.

The study has shown that there would likely be over-use of antimalaria drugs due to lack of laboratory confirmation of the malarial episodes as the treatment was based mainly on symptoms without laboratory confirmation. Malaria symptoms are non-specific and it is therefore possible some febrile illnesses that were treated as malaria were actually not malaria cases.

Fansidar was the anti-malaria drug used by most of the patients and appears to be the most widely used drug for malaria for those who self-prescribe due cheaper cost of the drug compared to other antimalarial drugs such as coartem which is Zambia ministry of health recommended 1st line drug for uncomplicated malaria.

There was a lot of information flow on malaria in these communities through friends and relatives, such sources of information may be inaccurate and lead to distortion of facts and misconceptions on the disease. Overcrowding and delay in attending to patients at government health facilities has increased self-medication among the community members, who lack adequate knowledge on the disease. Self-medication is often associated with emergence of drug resistance, it would be a worst of resources to continue changing drugs without understanding the causes of treatment failures or resistant of some drugs. Therefore providing people with formal education, better income and better 
health services may help in counteracting self-medication.

\section{Limitation}

The knowledge captured on patients younger than 15 years, could not be generalized as the information was obtained from their parents or guardians. The owners of some drug stores were not comfortable with such information be collected from their patients as most them are not legally allowed to sell prescription drugs to the public and in that regard they did not allow much time with their patients.

\section{Recommendations}

1. Only registered drug outlets should be allowed to sell antimalaria drugs, as most unregistered outlets offer antimalarial drugs to patients without a prescription. drug.

2. Increase emphasis on the recommended 1st line anti-malaria

3. Knowledge on the need for laboratory diagnosis of malaria need to be addressed among the community members to avoid the emergence of drug resistance.

4. Most of the respondents attributed their lack of seeking treatment at the health facilities to overcrowding and delays hence the need to improve on the number of health workers.

\section{Acknowledgment}

The authors offer their sincere thanks to Copper belt University for allowing this research to be conducted. Furthermore, gratitude is extended to the community members of Masala and drugstore owners and all those who helped in the study without which this study would not have been possible.

\section{Patient Questionnaire}

District:

Township:

Questionnaire\#.

Date: .............

1. Sex

A. Male

B. Female

2. Age

A. $<5$ years

B. 5 - 15 years

C. $>15$ years

3. What is your occupation?

A. Professional

B. Housewife

C. Businessman/woman

D. Others

4. What is your level of education?

B. Tertially

C. Secondary

D. Primary

5. What is your monthly income?

A. Below k500
B. $k 500-k 1000$

C. Above k1000

6. Do you have Malaria?

A. Yes

B. No

7. If answer to question 6 is $A$, then proceed to ask. How can one know it is malaria?

8. Can I ask you some questions about malaria?

A. YES

B. NO

9. What causes malaria?

10. What anti-malarial drug(s) is/are currently recommended by the Ministry of Health for treatment of simple (uncomplicated) malaria?

11. Which antimalarial drug do you buy the most?

A. Coartem

B. Fansidar

D. Quinine

E. Others (Specify)

12. What are the reasons for the choice of the antimalarial that you buy?

A. Cost

B. Effectiveness

C. Duration of treatment

D. Others (specify)

13. Have you ever received any information on malaria?

A. YES

B. NO

14. What are the sources of information on malaria in this community?

A. Friends

B. Community Health Worker

C. Radio

D. Health Centre

E. Other (specify)

15. What type of information have you received on malaria?

A. Signs and symptoms of malaria

B. Dangers

C. Drugs used

D. Use of protective measures

E. Other (specify)

16. Why do you sometimes not seek treatment at the Health Centre when you have malaria?

A. Distance is too far 
Citation: Mulenga C, Kawimbe B (2015) Self-treatment of Uncomplicated Malaria at Community Level in Masala Township, Ndola District, Zambia: Prevalence, Knowledge and Factors Influencing Self-treatment. Malar Cont Elimination 4: 133. doi: 10.4172/ 2470-6965.1000133

Page 6 of 3

\section{B. Overcrowding at the heath facility \\ C. Do not receive proper treatment \\ D. Not able to afford cost of treatment}

17. Are you able to reach the nearest health facility within 1 hour walking?

A. YES

B. NO

18. Are you able to be attended to at the health facility in less than 2 hours after arrival at the health facility?
A. YES
B. NO

\section{END OF INTERVIEW}

\section{References}

1. Manson-Bahr PEC, Bell DR. Malaria and babesiosis. In Manson's tropical diseases, 19thedtn. London, Bailliere Tindall.

2. WHO. A global strategy for malaria control. WHO Geneva.
3. WHO. Malaria twelfth programme report of the UNDP/World Bank/WHO specialprogramme for Research and Training in Tropical disease. Tropical Disease ResearchProgress 1975-94: Highlights 1993-94. WHO, Geneva 1995: $57-76$.

4. NMCC (2000): Malaria in Zambia - situation analysis March 2000. National Malaria Control Centre/CBoH Report.

5. Mukonde (1999) Factors contributing to high malaria fatality rate in all age groups in Chavuma District, Zambia. Essential Health Care Package in Zambia Bibliography An Annotated Review of Studies on the Essential Health Care Package, Central Board of Health, 1990 - 1998: 164.

6. Mnyika KS, Killewo JZ, Kabalimu TK (1995). Self-medication with antimalaria drugs in Dares-Salaam, Tanzania. Trop Georg Med 47: 32-34.

7. Marsh VM, Mutemi WM, Willetts A, Bayah K, Were S, et al. (2004) Improving malaria home treatment by training drug retailers in rural Kenya. Tropical Medicine International Health 9: 451-460.

8. Tavrow P, Shabahang J, Makama S (2002) Vendor-to-Vendor Education to improve malaria treatment by drug outlets in Kenya. Operations Research Results. Bethsda, MD: Published for the U.S. Agency for International Development (USAID) by the Quality Assurance (QA) project.

9. Kigodi KN, Komanya M (2005) Malaria and Anti-malarial Drugs Utilization among adults in a rural coastal community of Tanzania: knowledge,attitude and practice study. 